\title{
Possibility Enhanced Recovery Program in Emergency Surgical Treatment of Patients with Colorectal Obstructive Cancer
}

\author{
Sizonenko $N A^{1,2^{*}}\left(\mathrm{D}\right.$, Surov $D A^{1}$, Soloviev $I^{1}{ }^{1}$, Demko $A E^{1,2}$, Babkov OV ${ }^{2}$, Martynova \\ $G V^{2}$, Sviatnenko $A V^{1,2}$, Osipov $A V^{1,2}$, Yastrebov $I^{2}$ and Bezmozgin $B G^{2}$
}

${ }^{1}$ SM Kirov Military Medical Academy, Russia

${ }^{2}$ Saint-Petersburg II Dzhanelidze Research Institute of Emergency Medicine, Russia

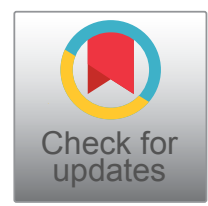

*Corresponding author: Nikolay A Sizonenko, SM Kirov Military Medical Academy, Saint Petersburg, Russia; SaintPetersburg II Dzhanelidze Research Institute of Emergency Medicine, Saint Petersburg, Russia

\section{Abstract}

Over the last years, the number of publications devoted to the concept of enhanced recovery after surgery (ERAS) in emergency abdominal surgery application increases. The purpose of this study was a comparative analysis of the results of the ERAS-program application in surgical treatment of the patients with colorectal cancer complicated by large bowel obstruction (LBO).

The study included 89 patients with obstructive colorectal carcinoma (OCRC), divided in the ERAS and control group ( $n=45$ and $n=44$, respectively).

During the treatment of the patients of the ERAS group in preoperative period, the following measures were taken: Patient information, his psychological preparation, prevention of postoperative pain, nausea and vomiting, thromboembolic and infectious complications. Intraoperative measures included local anesthesia of the skin in the line of laparotomy access, colon and small (under indications) intestines decompression, small intestine lavage, embryology oriented surgery and D3 lymphadenectomy, temporary installation of polyurethane catheter distal to the ligament of Treitz for early enteral nutrition, rectus sheath catheterization to carry out rectus sheath block of the anterior branches of the spinal nerves, control drainage installation into the small pelvis. In postoperative period, the early mobilization, urinary catheter and drainage removal after the patient transfer from intensive care unit were carried out.

The following criteria were used as the criteria for comparative evaluation: pain syndrome intensity, need for analgesics, time of enteric deficiency arresting, postoperative complications and mortality, postoperative period duration, and patients' life quality after discharge from the hospital.

It has been established that the proposed original ERAS program for this category of the patients is safe and effective due to improving the immediate results of surgical treatment.
\end{abstract}

\author{
Keywords \\ Colorectal cancer, Large bowel obstruction, Enhanced re- \\ covery after surgery, Fast track
}

\section{Introduction}

Colorectal cancer is the steadily occupying the leading positions in the structure of cancer morbidity in the world according to World Health Organization data $[1,2]$. A specificity of this pathology is a high incidence of life-threatening complications, the most frequent (up to $70 \%$ ) of which is LBO. This complication develops in $20-40 \%$ of the patients wich CRC, the majority of which belongs to elderly and senile age group (50-80\%) and, as a rule, has an unfavorable premorbid status. In addition, an important clinical feature in case of colon obstruction is the lack of distant metastases in patients, which significantly increases the requirements for the surgical care organization and scope. A high incidence of postoperative complications (35-50\%), as well as a significant postoperative mortality, which can reach $50 \%$, continues to persist [3-7].

In our opinion, it is necessary to distinguish three main components of the problem. First, the objective severity of the patients' condition (age, premorbid status) and the life-threatening complication that has developed as a result of oncological process, which inevitably causes the significant failures of basic metabolism and immune deficiency, which to a large extent determine the unsatisfactory short-term results. Secondly, the

Citation: Sizonenko NA, Surov DA, Soloviev IA, Demko AE, Babkov OV, et al. (2020) Possibility Enhanced Recovery Program in Emergency Surgical Treatment of Patients with Colorectal Obstructive Cancer. Int J Crit Care Emerg Med 6:102. doi.org/10.23937/2474-3674/1510102

Accepted: April 13, 2020: Published: April 15, 2020

Copyright: (C) 2020 Sizonenko NA, et al. This is an open-access article distributed under the terms of the Creative Commons Attribution License, which permits unrestricted use, distribution, and reproduction in any medium, provided the original author and source are credited. 
need for simultaneous solution during the emergency surgery of two, at first sight, incompatible tasks: Severe complication elimination and oncological radicalism provision, which, as is known, is a significant and independent predictor of survival rate. Thirdly, low number, according to the world literature data, of effective and purposeful attempts to integrate modern achievements of elective colorectal surgery into operative measures system for the patients with LBO of tumor genesis.

One of the potential directions for improving the immediate results of surgical treatment of the patients of this category is concept of fast track surgery or enhanced recovery after surgery - ERAS, proposed more than 20 years ago by Henrik Kehlet [8-11]. Strongly demonstrating its absolute clinical and economic effectiveness in elective surgery, this program, for different reasons, has not found general application in the surgery of complicated CRC at present. In some publications the preliminary results of clinical approbation of the ERAS within the surgical treatment of patients with LBO of tumor genesis are stated [12-14].

At the same time, the enhanced recovery program
(ERP) application, with obvious advantages, can open broad horizons for operative interventions short-term results significant improvement in these patients.

The purpose of this study was a comparative analysis of ERP application results in the surgical treatment of patients with colorectal cancer complicated by LBO.

\section{Materials and Methods}

A randomized clinical trial, previously approved by the Independent Ethics Committee, included 89 patients with LBO of tumor genesis, who were admitted by acute indications to the clinic. Randomization was carried out using the tables of random numbers. The study included only the patients with decompensated colonic obstruction. Exclusion criteria were: Widespread peritonitis, multiple organ dysfunction and associated complications of cancer (bleeding, perforation, abscess). In addition, with intraoperative detection of non-tumor causes of obstruction or tumor localization in the rectum, patients were also excluded from the study conducted.

Table 1: Patient characteristics and operative details.

\begin{tabular}{|c|c|c|c|}
\hline Indicator & ERAS group $(n=45)$ & control group $(n=44)$ & $P$ \\
\hline Age (Me) & $70(63.75 ; 80.25)$ & $70.5(61 ; 78.75)$ & 0.515 \\
\hline \multicolumn{4}{|l|}{ Sex, n (\%) } \\
\hline Male & $19(42.2)$ & $20(45.5)$ & 0.94 \\
\hline Female & $26(57.8)$ & $24(54.5)$ & 0.973 \\
\hline \multicolumn{4}{|l|}{ Location of cancer, $\mathrm{n}(\%)$} \\
\hline Cecum & $7(15.5)$ & $6(13.6)$ & 0.923 \\
\hline Ascending & $4(8.9)$ & $3(6.8)$ & 0.84 \\
\hline Hepatic flexure & $1(2.2)$ & $2(4.6)$ & 0.55 \\
\hline Transverse & $4(8.9)$ & $3(6.8)$ & 0.84 \\
\hline Splenic flexure & $5(11.1)$ & $4(9.1)$ & 0.887 \\
\hline Descending & $4(8.9)$ & $5(11.4)$ & 0.832 \\
\hline Sigmoid & $12(26.7)$ & $10(22.7)$ & 0.91 \\
\hline Recto-sigmoid & $8(17.8)$ & $11(25)$ & 0.778 \\
\hline \multicolumn{4}{|l|}{ Types of surgery, $n(\%)$} \\
\hline Right hemicolectomy & $12(26.7)$ & $13(29.5)$ & 0.927 \\
\hline $\begin{array}{l}\text { Left obstructive resection } \\
\text { (of Hartmann`s procedure type) }\end{array}$ & $33(73.3)$ & $31(70.5)$ & 0.987 \\
\hline Duration of obstruction, day (SD) & $3.8 \pm 1.2$ & $3.6 \pm 1.5$ & 0.45 \\
\hline Operative duration, $\min (\mathrm{Me})$ & $175(140 ; 222.5)$ & $200(151.25 ; 240)$ & 0.822 \\
\hline Anesthesia duration, $\min (\mathrm{Me})$ & $222.5(183.75 ; 280)$ & $260(205 ; 290)$ & 0.71 \\
\hline \multicolumn{4}{|l|}{ ASA, n (\%) } \\
\hline$\leq 3$ & $27(60)$ & $24(54.5)$ & 0.95 \\
\hline$>3$ & $18(40)$ & $20(45.5)$ & 0.91 \\
\hline \multicolumn{4}{|l|}{ CR-Possum } \\
\hline Morbidity, \% (Me) & $52.5(29.5 ; 71.75)$ & $45(37 ; 64.5)$ & 0.229 \\
\hline Mortality, \% (Me) & $19.5(10 ; 33.75)$ & $21.5(14.5 ; 34.5)$ & 0.62 \\
\hline Co-morbidity index (Charlson), (SD) & $8.13 \pm 2.92$ & $7.96 \pm 2.15$ & 0.26 \\
\hline
\end{tabular}


All the patients $(n=89)$ were divided into two groups: The ERAS group, in which the ERP was applied $(n=45)$, and the control group, where the patients received traditional surgical treatment $(n=44)$. Patients of both groups were comparable by sex, age, degree of operative and anesthetic risk (ASA), physiology and operative severity score, morbidity and mortality predictable (CR-POSSUM), co-morbidity index (Charlson), tumor location and type of surgery (Table 1). All the patients included in the study performed partial resections of colon various parts with the total mesocolonectomy: Right hemicolectomy or left obstructive resections (of Hartmann`s procedure type).

When treating the patients of the ERAS group, the following ERP components were used: In preoperative period - a detailed information about the patient's condition, planned surgery and postoperative period features, his training to do early postoperative follow-up activities, anterior abdominal wall skin marking (presumed and alternative) for possible colostomy, postoperative nausea, vomiting, as well as insulin resistance, thromboembolic and infectious complications prevention. Intraoperative activities included local skin anesthesia in the line of laparotomy access, large and small (according to indications) intestines decompression, small intestines lavage with polyelectrolyte mixtures with antihypoxant, embryology oriented surgery and D3 lymphadenectomy, rejection of prolonged nasoga- strointestinal intubation and temporary installation of polyurethane catheter distal to the ligament of Treitz for early enteral nutrition, one control drainage installation into the small pelvis and sheath of rectus muscle of abdomen catheterization with the aim of prolonged postoperative pain relief. In postoperative period, the early follow-up care measures were performed within the bed immediately after extubation in the intensive care unit, early vertical orientation, urinary catheter and drainage from the pelvis removal after the patient transfer to the surgical department. In addition, the use of opioid analgesics was excluded and the volume of targeted fluid therapy, which was terminated after the onset of early enteral nutrition, was minimized. The detailed ERP of the patients' in the ERAS group is presented in Table 2.

The following indicators were analyzed as the criteria for comparative evaluation of ERP approval results:

- Pain syndrome intensity (numerical rating scale NRS);

- Time of enteral deficiency elimination (the noises of intestinal peristalsis occurrence, passage of flatus and stool, myoelectrical activity of the gastrointestinal tract);

- Patient's «readiness» timing to be discharged after surgery (questionnaire QoR-40) [15];

Table 2: ERP components in the surgical treatment of patients with LBO of tumor genesis.

\begin{tabular}{|c|c|c|}
\hline Preoperative period & Intraoperative period & Postoperative period \\
\hline $\begin{array}{l}\text { - Detailed information to the patient } \\
\text { (immediate family member), } \\
\text { psychological training }\end{array}$ & $\begin{array}{l}\text { - Local infiltration anesthesia along the skin } \\
\text { incision line }\end{array}$ & $\begin{array}{l}\text { - Early activation (a complex of } \\
\text { rehabilitation actions within the bed } \\
\text { immediately after extubation into the } \\
\text { intensive care unit) }\end{array}$ \\
\hline $\begin{array}{l}\text { - Front belly wall skin marking (presumed } \\
\text { and alternative) for possible colostomy }\end{array}$ & - Colon decompression & $\begin{array}{l}\text { - Early vertical orientation (the first } \\
\text { day of postoperative period) }\end{array}$ \\
\hline $\begin{array}{l}\text { - Mechanical preparation of the colon } \\
\text { substenotic part (within the framework of } \\
\text { conservative treatment) }\end{array}$ & $\begin{array}{l}\text { - Single-step decompression and lavage of } \\
\text { the small intestine (under indications) }\end{array}$ & $\begin{array}{l}\text { - Urinary catheter removal after } \\
\text { transfer to the clinic }\end{array}$ \\
\hline $\begin{array}{l}\text { - Postoperative insulin resistance } \\
\text { prevention }\end{array}$ & $\begin{array}{l}\text { - Enteral therapy (polyelectrolytic mixtures, } \\
\text { antihypoxants) }\end{array}$ & $\begin{array}{l}\text { - Drain tube removal from the pelvis } \\
\text { in the first day after the surgery }\end{array}$ \\
\hline $\begin{array}{l}\text { - Postoperative nausea and vomiting } \\
\text { prevention }\end{array}$ & $\begin{array}{l}\text { - Embryology oriented surgery and D3 } \\
\text { lymphadenectomy }\end{array}$ & - Early enteric nutritional support \\
\hline $\begin{array}{l}\text { - Thromboembolic complications } \\
\text { prevention (compression stockings) }\end{array}$ & $\begin{array}{l}\text { - Long-term nasogastrointestinal intubation } \\
\text { rejection }\end{array}$ & $\begin{array}{l}\text { - Volume and duration of infusion } \\
\text { therapy reduction with enteral } \\
\text { support increase }\end{array}$ \\
\hline - Infectious complications prevention & $\begin{array}{l}\text { Temporary installation of polyurethane } \\
\text { catheter distal to the ligament of Treitz for } \\
\text { early enteral nutrition }\end{array}$ & - Prokinetics usage \\
\hline \multirow[t]{3}{*}{ - Pain syndrome prevention } & $\begin{array}{l}\text { - Small pelvis draining } \\
\text { - Sheath of rectus muscle of abdomen } \\
\text { catheterization for postoperative pain relief }\end{array}$ & $\begin{array}{l}\text { - Early oral nutrition } \\
\text { - Preventive antibiotics within 48-72 } \\
\text { hours of postoperative period }\end{array}$ \\
\hline & & $\begin{array}{l}\text { - Postoperative muitimodal } \\
\text { analgesia (segmental anesthesia, } \\
\text { NSAIDs, opioid analgesics rejection) }\end{array}$ \\
\hline & & $\begin{array}{l}\text { - Anticoagulants from the first day of } \\
\text { postoperative period }\end{array}$ \\
\hline
\end{tabular}


- Postoperative period duration;

- Postoperative morbidity (frequency and severity of postoperative complications by Clavien-Dindo classification) [16];

- Postoperative mortality;

- Patients' quality of life after surgery (MOS SF-36 questionnaires, Barthel scale).

In addition, the percentage of activities included in the guidelines for perioperative care in elective colonic surgery (2012) [17].

All the data was prepared and compiled using the Excel Microsoft Office 2010 computer program. A statistical analysis was performed in Statistica 10.0 program. Data are analyzed using the descriptive and analytical statistics. To test the nature of data distribution, the Kolmogorov-Smirnov test was used. A paired t-test was used to compare data between these two groups when they showed a normal distribution. The Mann-Whitney $U$ test was used when the data did not have normal distribution. Pearson's $\chi^{2}$ or Fisher's exact test were used for categorical data. A p-value less than 0.05 was considered as statistically significant. Most of the results are presented in the form of indicator median indicating $25^{\text {th }}$ and $75^{\text {th }}$ percentiles.

\section{Results}

\section{ERAS group}

The pain syndrome after surgery did not exceed 5-6 points on the first day with a gradual regression to $0.5-1$ points to day $4-5$. There was no need to use the opioid analgesics. A shorter period of the gastrointestinal tract functions recovery was observed in patients: Nausea and vomiting absence, enteral feeding was started, on average, 36-48 $\mathrm{h}$ after the surgery, with intestinal peristalsis noise occurrence during the first day, and the passage of flatus - within 24-36 $\mathrm{h}$, defecation - 2-3 d after the surgery. The gastrointestinal tract (GIT) motor and evacuation functions early recovery, enteral deficiency timeIy elimination, as well as reliable pain management were clearly reflected in the results of 34 patients (75.6\%) of this group "readiness» to discharge from hospital for follow-up care (outpatient therapy, day hospital) to day 5 of postoperative period objective assessment (under early postoperative complications absence). On average, the duration of postoperative period was $8.67 \pm 1.7 \mathrm{~d}$. Eight cases of postoperative complications were noted: 6 - of I-IIla grade and 2 of IIIb-IV grade according to Clavien-Dindo classification. Mortality was $14 \%(n=6)$. The recovery to initial level of quality of life indicators, as well as physical and psychological components of health on day 30 after discharge from the hospital were observed in 29 patients (64.4\%).

\section{Control group}

The pain syndrome in the early postoperative period which reached 7-8 points was observed in 26 patients (59.1\%), thus requiring use of opioid analgesics in 11 patients $(25 \%)$. It should be noted that the majority of patients ( $n=36,81.8 \%$ ) have the pain syndrome at the level of 4-5 points for 4 days of postoperative period. The attention was given to GIT motor activity slow recovery, which was manifested by nausea and vomiting in 23 patients (52.3\%) during 36-72 $\mathrm{h}$ after the surgery. In addition, the intestinal peristalsis noise occurrence was noted, on average, only to the end of day 2, the onset of flatus passage - 2-3d and defecation - 3-4 d, respectively. Objective "readiness" for discharge from hospital, based on the questionnaire, was registered on day 9 of postoperative period, the average duration of which was $14 \pm 2.3 \mathrm{~d}$. 13 cases of early postoperative complications were registered: 8 - of I-IIla grade and 5 - of IIIb-IV grade according to Clavien-Dindo classification. It should be noted that to correct postoperative complications, 4 patients $(9 \%)$ required relaparotomy. Postoperative mortality was $25 \%(n=11)$. Quality of life indicators were reduced, mainly due to self-care ability, pain, emotional and social functioning slow recovery.

\section{Discussion}

The satisfactory results obtained to date in the study, in our opinion, represent ERP use high effectiveness and safety in the surgical treatment of patients with LBO of tumor genesis. It should be noted that the ERP developed and used in emergency surgery is, in fact, the result of the adaptation of the recommendations of the ERAS society for perioperative care in elective colonic surgery (2012) [17]. It is evident that a number of provisions that cannot be applied in emergency situation have been excluded from the proposed multimodal program. At the same time, a significant positive role in fundamental improvement of short-term results of the surgical treatment of patients with complicated CRC was played such components as the rejection of prolonged nasogastrointestinal intubation, large and small (according to indications) intestines intraoperative decompression, early enteral therapy and nutritional support, number of drain tubes minimization, early removal of probes and catheters, and widespread use of regional analgesia.

In our opinion, the intraoperative stage, namely, embryology oriented surgery and D3 lymphadenectomy is of particular importance for ERP successful implementation in emergency surgery. This all-important component plays, in fact, a core role for the entire postoperative component of the proposed multimodal ERP. Preliminary central ligation of the main vessels, along with the principal rejection of "transmesocolar» partial resections in favor of re- 
moved organocomplex mobilization within the conjugation fascia boundaries, allows not only to minimize a blood loss and ensure a high safety of intervention, but also to obtain a high-quality drug that fully meets the modern requirements of oncological radicalism within the so-called "specimen-oriented surgery". The injury rate of a widespread open surgical intervention reduction in certain, and in our opinion, significant level lows down its unconditional disadvantages in comparison with laparoscopic technic, which, as is known, is a key element in the principle of operative access minimization implementation within the fast track concept in colorectal surgery. Despite the seeming contradictory nature of above-mentioned condition, exactly this one creates the prerequisites for sufficiently ambitious tactical decisions making in terms of common tendencies in urgent surgery (early removal of drain tubes, catheters, probes, etc.). It should be noted that the ideology of modern principles of oncological radicalism application in emergency surgery of complicated CRC is currently being discussed in the world scientific literature and is considered as the most upcoming trend for the modern operative surgery development [18].

In general, $63-68 \%$ of ERP components recommended by the ERAS society for use in elective colonic surgery (2012) were used in the adapted multimodal program of enhanced recovery after urgent surgery in patients with OCRC.

The principles that underlie the modern tactics of surgical treatment of this category of patients must be separately discussed. The fundamental circumstance that determined the success of adopted ERAS concept application in emergency surgery of complicated CRC is, in our opinion, the identity of its pathogenetic content and principles of LBO of tumor genesis surgical treatment modern tactics.

What determines the prospects of ERP successful implementation in emergency surgery and improvement of its results? Refusing the concept analysis based on the principles of ERAS individual components' effects description, we can state that the perioperative multimodal techniques complex application in emergency surgery creates the necessary conditions for the key task of emergency surgery effective solution - the life-threatening complication elimination. In this regard, one of the basic conditions is the timely weakening of hypercatabolic metabolic response to emergency surgery, which lies within the metabolic optimized fast track concept (MOFA), the purpose of which is, first of all, to provide the necessary conditions for multiple organ dysfunction effective multicomponent intensive therapy, inevitably, to some extent, causing the postoperative complications and mortality [19]. A multiple organ dysfunction in patients with LBO, as a rule, develops against the background of expressed co-morbidity decompensation. In this case, the trigger mechanism, in our opinion, based on ERAS concept pathophysiological analysis, is an enteral deficiency with its regular manifestations in the form of dismetabolic, including trophological, protein-energetic, water-electrolytic, acid-base and, as a rule, immune alterations. The persistence and intensity of these pathological consequences of decompensated colon obstruction determine the vector and dynamics of multiple organ dysfunction development in this category of the patients. Exactly these pathological syndromes are the purpose of direct or indirect, but, as preliminary results of the randomized trial showed, high-efficiency effect of various ERP components in patients with complicated colorectal cancer.

Timely elimination and prevention of key pathogenetic factors as a natural result affected the shortterm results of patients' surgical treatment. First of all, the use of the multimodal enhanced recovery system significantly reduced the incidence of postoperative complications, mainly of IIIb-IV grade according to Clavien-Dindo classification. A natural consequence of "severe» complications incidence reduction was, on the one hand, a reduction in postoperative mortality, and on the other hand - a reduction in duration of postoperative period. Moreover, the obvious, but still important, in our opinion, dependence of postoperative period duration on the complications and their severity availability should be noted. In case of uncomplicated subsequent period of his life in the ERAS group was $8 \mathrm{~d}$; under complications of I-Illa grade - $17 \mathrm{~d}$, and under complications of IIIb-IV degree - up to $40 \mathrm{~d}$, respectively. Thus, an analysis of preliminary results of the study allows making a number of conclusions.

Firstly, the ERAS ideology application in emergency surgery of complicated colorectal cancer is a possible, safe and effective technology that provides a significant improvement of its immediate results.

Secondly, the main clinical effect of ERP principles implementation is a reduction in postoperative, primarily "severe» complications (of IIIb-IV grade according to Clavien-Dindo) and, as a consequence, mortality.

Thirdly, ERP allows reducing the duration of postoperative period to 8 days in case of its uncomplicated course.

Fourthly, it should be noted that, in general, the short-term results of surgical treatment of the patients with LBO of tumor genesis in cases of the developed enhanced recovery program application are comparable with the same ones of elective surgical treatment of the patients with colon cancer. The latter circumstance, considering the nature of the main disease, the severity of complications and the extremely unfavorable premorbid background in patients with LBO, merits special attention. 
In our opinion, it can be stated with certainty that ERS introduction into the practice of emergency surgery is a modern and the most promising strategy of the patients with OCRC treatment results improvement.

\section{References}

1. Ferlay J, Soerjomataram I, Dikshit R, Eser S, Mathers C, et al. (2015) Cancer incidence and mortality worldwide: Sources, methods and major patternsin GLOBOCAN 2012. Int J Cancer 136: E359-E386.

2. Robertson J, Barr R, Shulman LN, Forte GB, Magrini N (2016) Essential medicines for cancer: WHO recommendations and national priorities. Bull World Health Organ 94: 735-742.

3. Malvezzi M, Carioli G, Bertuccio P, Boffetta P, Levi F, et al (2018) European cancer mortality predictions for the year 2018 with focus on colorectal cancer. Ann Oncol 29: 10161022.

4. Merkel S, Meyer C, Paradopoulos T, Meyer T, Hohenberger W (2007) Urgent surgery in colon carcinoma. Zentralbl Chir 132: 16-25.

5. Milojković $B$, Mihajlović $D$, Ignjatović $N$, Janjić $D$, Dimitrijević $M$, et al. (2015) Surgical treatment of acute intestinal obstruction caused by colorectal cancer. Acta Medica Med 54: 18-22.

6. Totikov ZV, Totikov VZ (2017) The possibilities to improve the outcomes in patients with colon cancer complicated by acute obstruction. Khirurgiia (Mosk) 17-23.

7. Zahid A, Young CJ (2016) How to decide on stent insertion or surgery in colorectal obstruction? World J Gastrointest Surg 8: 84-89.

8. Kehlet H, Dahl JB (2003) Anaesthesia, surgery, and challenges in postoperative recovery. Lancet 362: 1921-1928.

9. Kehlet H, Wilmore DW (2008) Evidence-based surgical care and the evolution of fast-track surgery. Ann Surg 248: 189-198.
10. Kehlet H, Wilmore DW (2002) Multimodal strategies to improve surgical outcome. Am J Surg 183: 630-641.

11. Kehlet H (1997) Multimodal approach to control postoperative pathophysiology and rehabilitation. $\mathrm{Br} \mathrm{J}$ Anaesth 78: 606-617.

12. Lohsiriwat V (2014) Enhanced recovery after surgery vs conventional care in emergency colorectal surgery. World J Gastroenterol 20: 13950-13955.

13. Roulin D, Blanc C, Muradbegovic M, Hahnloser D, Demartines N, et al. (2014) Enhanced recovery pathway for urgent colectomy. World J Surg 38: 2153-2159.

14. Shida D, Tagawa K, Inada K, Nasu K, Seyama Y, et al. (2017) Modified enhanced recovery after surgery (ERAS) protocols for patients with obstructive colorectal cancer. BMC Surg 17: 18.

15. Shida D, Wakamatsu K, Tanaka Y, Yoshimura A, Kawaguchi M, et al. (2015) The postoperative patient-reported quality of recovery in colorectal cancer patients under enhanced recovery after surgery using QoR-40. BMC Cancer 15: 799.

16. Dindo D, Demartines N, Clavien PA (2004) Classification of surgical complications: A new proposal with evaluation in a cohort of 6336 patients and results of a survey. Ann Surg 240: 205-213.

17. Gustafsson UO, Scott MJ, Schwenk W, Demartines N, Roulin D, et al. (2013) Guidelines for perioperative care in elective colonic surgery: Enhanced Recovery After Surgery (ERAS) Society recommendations. World J Surg 37: 259284.

18. Teixeira $F$, Akaishi $E H$, Ushinohama AZ, Dutra TC, Netto $S D$, et al. (2015) Can we respect the principles of oncologic resection in an emergency surgery to treat colon cancer? World J Emerg Surg 10: 5.

19. Looft VM, Dmitriev AV (2017) The Metabolic Optimized Fast Track Concept: Preoperative preparation for abdominal surgery. Khirurgiia (Mosk) 10: 65-71. 